\title{
Osteosarcopenia: Where bone, muscle and fat collide
}

Henry Porta Hirschfeld, $\mathrm{MD}^{1}$, Rita Kinsella, $\mathrm{PT}^{2}$, Gustavo Duque, $\mathrm{MD}, \mathrm{PhD}^{2,3}$

${ }^{1}$ Department of Geriatrics and Gerontology - Federal University of São Paulo, 1500 Sena Madureira Avenue, São Paulo, Brazil.

${ }^{2}$ Australian Institute for Musculoskeletal Science (AIMSS), University of Melbourne and Western Health, 176 Furlong Road, St. Albans, VIC, 3021 Australia.

${ }^{3}$ Department of Medicine, Melbourne Medical School - Western Health, The University of Melbourne, St. Albans, VIC 3021 Australia.

Correspondence to: Prof. Gustavo Duque, MD, PhD, FRACP

Australian Institute for Musculoskeletal Science (AIMSS)

The University of Melbourne and Western Health

Level 3 WCHRE Building, 176 Furlong Road, St Albans VIC 3021

Tel: +61 38395 8121; Facsimile: +61 383958258

Email: gustavo.duque@unimelb.edu.au 


\begin{abstract}
As the world's population ages, the prevalence of chronic diseases increases. Sarcopenia and osteoporosis are two conditions that are associated with aging, with similar risk factors that include genetics, endocrine function and mechanical factors. Additionally, bone and muscle closely interact with each other not only anatomically, but also chemically and metabolically. Fat infiltration, a phenomenon observed in age-related bone and muscle loss, is highly prevalent and more severe in sarcopenic and osteoporotic subjects. Clinically, when individuals suffer a combination of both disorders, negative outcomes such as falls, fractures, loss of function, frailty and mortality increase, thus generating significant personal and socio-economic costs. Therefore, it is suggested that when bone mineral density loss is synchronic with decreased muscle mass, strength and function, it should be interpreted as a single diagnosis of osteosarcopenia, which may be preventable and treatable. Simple interventions such as resistance training, adequate protein and calcium dietary intake, associated with maintenance of appropriate levels of vitamin $\mathrm{D}$, have a dual positive effect on bone and muscle, reducing falls, fractures and consequently, disability. It is essential that fracture prevention approaches - including post-fracture management - involve assessment and treatment of both, osteoporosis and sarcopenia. This review summarizes osteosarcopenia epidemiology, pathophysiology, diagnosis, outcomes and potentially combined management.
\end{abstract}

Keywords: Osteosarcopenia; sarco-osteopenia; osteoporosis; sarco-osteoporosis; sarcopenia; falls.

Conflicts of interest: The authors have no conflicts of interest to disclose.

Mini-Abstract: In older persons, the combination of osteopenia/osteoporosis and sarcopenia has been proposed as a subset of frailer individuals at higher risk of institutionalization, falls, and fractures. This review summarizes osteosarcopenia epidemiology, pathophysiology, diagnosis, outcomes and management. 


\section{Introduction}

The world's population is rapidly ageing increasing the prevalence of many chronic diseases more commonly seen in older patients. Sarcopenia and osteopenia/osteoporosis are two chronic conditions, which are frequently diagnosed in frail older patients, both placing significant burden on the individual as well as more widely across public health domains $[1,2]$.

The etymology of the term sarcopenia comes from the Greek words sarx, meaning muscle, and penia, meaning loss and refers to the aged-related progressive and generalized loss of skeletal muscle mass along with impaired muscle function (strength or physical performance) that characterizes this condition, which is also associated with negative impact on activities of daily living, frailty and increased risk of falls [3]. Osteopenia/osteoporosis is a systemic bone disease in which the bone microarchitecture deteriorates and the bone mineral density (BMD) reduces, increasing the bone fragility and the risk of fractures - even after minor falls. The differentiation between osteopenia and osteoporosis is mostly based on the results of the BMD in which subjects are considered osteopenic when BMD is between -1 and 2.5 SD whereas BMD below -2.5 SD is considered as osteoporosis [4].

Sarcopenia and osteoporosis share common risk factors and biological pathways and are associated with significant physical disability, representing a huge threat to loss of independence in later life [5]. It is intuitive that many older individuals, especially those frailer ones, would suffer from concurrent osteoporosis and sarcopenia, further increasing their risks and complications [6]. The combination of these two diseases exacerbates negative health outcomes and has been described as a "hazardous duet" adding the propensity of falls from sarcopenia to the vulnerability of bones in those with osteoporosis [7].

Bone and muscle are interconnected not only because of their adjacent surfaces but also chemically and metabolically. In addition, specific pathophysiological findings, such as fat infiltration and alterations in stem cell differentiation, are common to both diseases thus 
suggesting that sarcopenia and osteoporosis are closely linked. Therefore, the term osteosarcopenia has been proposed to describe individuals suffering from both diseases, which contributes to a higher risk of falls, fractures, institutionalization and poorer quality of life $[8,9]$. Consequently, it is reasonable that every fracture prevention approach should also include assessment of muscle mass and function to evaluate whether sarcopenia is also present. In the presence of osteosarcopenia, planned interventions should therefore address the strength of not only the bone but also the muscle.

\section{Epidemiology}

The peak of bone mass, which is reached at the end of the third decade of life, is followed by a progressive and slow decline. In post-menopausal women, this reduction is more severe. This implies that between the third and seventh decades, there is a reduction in bone mass of around 30\% [10, 11]. Based on data from the National Health and Nutrition Examination Survey III (NHANES III), there are more than 40 million older adults with osteopenia in the United States [12]. It is also estimated that a 50-year-old Caucasian woman has a 15 to $20 \%$ lifetime risk of hip fracture and one out of every two Caucasian women and one in five men will suffer an osteoporotic-related-fracture [13]. With the aging population, this "fracture epidemic'" is expected to exponentially grow by $2050[14,15]$. Indeed, there are predictions that by 2050 the incidence of hip fractures worldwide could exceed 21 million [16].

In contrast to bone, muscle mass reaches its peak earlier - around the age of 25 . Then, until the age of 50 years there is a slight reduction of $5 \%$ in the number of the muscle fibers. After then, the annual loss of muscle mass is between 1 to $2 \%$ per year resulting in a loss of about $30 \%$ of muscle mass at the age of 80 [17-19]. Muscle strength declines by $1.5 \%$ between 50 years and 60 years and by $3 \%$ thereafter [20]. Depending on the definition used, the prevalence of sarcopenia can reach $13 \%$ in individuals in the 60-70-year age bracket and up to 
$50 \%$ for those over the age of 80 [3]. Using one of the most accepted definitions provided by the European Working Group on Sarcopenia in Older People (EWGSOP), it is estimated there is a prevalence of $1-33 \%$ of individuals with sarcopenia in the community with higher prevalence in settings where older, more complex or acutely ill individuals are cared for [21]. It is therefore estimated that sarcopenia currently affects approximately 50 million people worldwide and will affect more than 200 million in the next 40 years [3].

Osteosarcopenia is a recent terminology, so there are relatively few studies assessing its epidemiology. A report of more than 300 women in Italy with hip fractures found that $58 \%$ were also sarcopenic [22]. Another study from England indicates that in post-menopausal women, the prevalence of sarcopenia was $25 \%$ for those with osteopenia and $50 \%$ for those with osteoporosis. In a cross-sectional study conducted in Australia in 2015 involving 680 community-dwelling older individuals with a history of falls, almost $40 \%$ were osteosarcopenic [6]. Also in 2015, a study of community-dwelling Chinese elders over 65 years, found a prevalence of osteosarcopenia in $10.4 \%$ of men and $15.1 \%$ of women with higher age (more than 80 years), frailty and a greater level of comorbidity independently associated with the likelihood of being osteosarcopenic [23].

\section{Pathophysiology}

Bone and muscle are metabolically active tissues, continuously regulated by the harmony of counteracting processes. Skeletal muscle protein synthesis is balanced by its degradation while bone formation is equilibrated by its reabsorption [24]. An imbalance in the regulation of these tissues can result in low BMD or sarcopenia. Both diseases are multifactorial and share various pathophysiological pathways. Apart from age, there are several other risk factors that play a role in the development of osteosarcopenia. Genetic polymorphisms of the genes GLYAT, methyltransferase-like 21C (METTL21C), myostatin, a-actinin 3, proliferator- 
activated receptor gamma coactivator 1-alpha (PGC-1 $\alpha)$ and myocyte enhancer factor $2 \mathrm{C}$ (MEF-2C) are related to bone and muscle loss [25, 26]. Endocrine disorders (mainly diabetes, abnormal thyroid function and low levels of vitamin D, sex steroids, growth hormone and insulin-like growth factor-1), malnutrition, obesity and use of corticosteroids are also associated with osteosarcopenia [26]. Both bone and muscle are adaptive, modifying their mass and strength in response to mechanical loading. Therefore, mechanical stimulus is essential for the health of both tissues and thus decreased level of physical activity may shift the delicate balance in favor of muscle degradation and bone resorption [27].

Fatty infiltration of muscle and bone, which was interpreted to be a natural age-related phenomenon in the past, is now known to contribute to osteosarcopenia, most likely related to the negative impact of the secretion of inflammatory cytokines by both bone marrow and body fat in a process known as lipotoxicity [28, 29]. It has been shown that sarcopenic and osteopenic patients have high serum concentrations of inflammatory cytokines, predominantly interleukin-6 (IL-6) and tumor necrosis factor alpha (TNF- $\alpha$ ) [30], which have been associated with both systemic and local lipotoxicity [28-30]. In addition, there is abundant evidence documenting that changes in bone mass are closely associated with changes in muscle mass. The clinical diagnosis of sarcopenia, demonstrates the positive correlation between the two tissues, with higher lean body mass associated with increased BMD and vice versa [30-32]. However, it is not clear whether the patients start their decline as sarcopenic or osteopenic.

The shared risk factors are not the only mechanisms that explain the synchronous loss of bone and muscle mass. Basic and clinical research suggests a "crosstalk" between the two tissues, with fat being a major player that affects this interaction. The musculoskeletal unit interacts mechanically and physically but also biochemically via paracrine and endocrine communication [26, 33]. There are many possible pathways involved in this interaction that can explain the development and progression of osteosarcopenia; however, it is a relatively new 
area of research, not yet fully understood. One of these mechanisms includes osteocalcin, an osteoblast-derived protein marker of bone formation which stimulates $\beta$-cell proliferation, insulin secretion and acts directly on skeletal muscle, correlating with muscle strength [34]. Another intrinsic mechanism linking muscle and bone is the secretion of vascular endothelial growth factor (VEGF) by bone marrow mesenchymal stromal cells, which stimulates myoblast proliferation [35]. The muscle also releases several endocrine molecules that affect bone such as insulin-like growth factor-1, osteoglycin, irisin, osteonectin, fibroblast-growth factor-2, IL-6, IL-15 and myostatin [36]. Myostatin is a member of the transforming growth factor-beta superfamily, expressed mainly in skeletal muscle with well-known effects on the inhibition of muscle growth by decreasing myoblast proliferation, and it may also have target effects on bone [37]. Myostatin gene deficiency and systemic administration of ACVR2B-Fc, a soluble myostatin decoy receptor, result in skeletal muscle hypertrophy and increase in bone mass [26]. Consequently, sarcopenia can contribute to the evolution of low BMD and vice versa. Figure 1 shows the risk factors of osteosarcopenia and the relationship of muscle and bone in the development of osteosarcopenia [26].

\section{Fig.1 here}

\section{Diagnosis}

\section{Osteopenia/Osteoporosis}

The gold standard to assess bone mass is dual X-ray absorptiometry (DXA). Osteopenia is defined based on the World Health Organization (WHO) criteria as a BMD between -1.0 and 2.5 standard deviations for a young healthy adult (T-score) and osteoporosis as a BMD of -2.5 standard deviations or below $[4,38]$. There are also several well-known clinical factors that can contribute to increased risk of fracture. The WHO Fracture Risk Algorithm (FRAX®) 
tool combines clinical risk factors with BMD to improve fracture risk estimation, however, it does not include specific risk factors or clinical outcomes of sarcopenia [9].

Although there is no consensus on what population should be screened for osteopenia/osteoporosis, there is agreement that DXA assessment of BMD should be performed in postmenopausal women 65 years and older, regardless of risk factors [39-41]. There is more controversy over BMD screening for men. The United States Preventive Services Task Force (USPSTF) has concluded that current evidence is insufficient to enable an assessment of the benefit versus harm of screening for osteoporosis in men [41] while the National Osteoporosis Foundation (NOF) and International Society for Clinical Densitometry (ISCD) recommend measurement of BMD in men age 70 years and older regardless of risk factors $[38,39]$ and the Canadian Osteoporosis Society recommends the screening even earlier, with men age 65 years or more [42]. Although there are differing opinions, there is consensus to screen younger population (50 to 65 years old) where additional clinical risk factors for fracture exist including previous fragility fracture, parental history of hip fracture, current smoking, high alcohol intake, use of glucocorticoids in a daily dose $\geq 5 \mathrm{mg}$ prednisone or equivalent for $\geq 3$ months, rheumatoid arthritis, malabsorption syndrome, hypogonadism or premature menopause and primary hyperparathyroidism [39, 40, 42].

\section{Sarcopenia}

The EWGSOP definition of sarcopenia is the presence of low muscle mass associated with low muscle function and strength [3]. As shown in Table 1, there are several techniques that can be used to assess sarcopenia. DXA is also an accepted way to assess the muscle mass (lean mass) in routine clinical practice or in the research scenario. Indeed, DXA is precise and less expensive than other body imaging techniques. Using the classification of Baumgartner [43], sarcopenia is defined as an appendicular skeletal muscle mass index value greater than 2 
standard deviations below the sex specific mean of a young healthy reference population $(<5.5 \mathrm{~kg} / \mathrm{m} 2$ for women and $<7.26 \mathrm{~kg} / \mathrm{m} 2$ for men). The appendicular skeletal muscle mass index is calculated by the appendicular muscle mass (derived as the sum of arm and leg lean body mass) divided by the square of the person's height in meters.

Bioelectrical impedance analysis is an alternative to DXA, being cheaper, readily reproducible and uses portable equipment $[44,45]$. However, it has been shown to be less precise, particularly in patients with edematous disease, such as heart failure, renal failure and lymphedema [46]. Anthropometric measures such as calf circumference or skin fold thickness are inaccurate, mainly because age-related changes in fat deposits, loss of skin elasticity, obesity and presence of edema can contribute to errors in the estimation of muscle mass. For that reason, anthropometric measures are not recommended for routine use for the diagnosis of sarcopenia, but may be an alternative when no other clinical measure is available. Calf measure is one of the most studied methods, with a threshold of less than $31 \mathrm{~cm}$ associated with low muscle mass and disability [3, 47].

Handgrip strength is the most preferable method of measuring muscle strength because of its simplicity, standardization and its good correlation with lower extremity muscle strength $[3,48]$. It is also a clinical marker of poor mobility and predictor of clinical outcomes. Table 2 shows the cut-off points adjusted by gender and body mass index (BMI) for handgrip strength [3]. The most frequently used method for assessment of physical performance is gait speed (over a 4-6-meter course). It is a known predictor of mobility limitations and mortality, with the most frequently used cut-off value being less than $0.8 \mathrm{~m} / \mathrm{s}$ [3].

The EWGSOP developed an algorithm for screening of sarcopenia in clinical practice as shown in Figure 2. EWGSOP suggests that people aged over 65 years or younger individuals at risk of sarcopenia should be screened, and it also proposed three stages for classifying sarcopenia. Low muscle mass alone characterizes the first stage named "pre-sarcopenia". The 
second stage, identified as "sarcopenia", is defined as the presence of not only low muscle mass but also decreased muscle strength or decreased physical performance. The third stage, "severe sarcopenia", is characterized as the presence of low muscle mass associated with a combination of decreased muscle strength and decreased muscular physical performance. Although this classification is not widely accepted, it facilitates the identification of those subgroups of patients at higher risk of poor outcomes.

\section{Fig. 2 here}

The Asian Working Group for Sarcopenia (AWGS) consensus takes similar approaches for sarcopenia diagnosis, but unlike EWGSOP, recommends measuring both muscle strength (hand-grip strength) and physical performance (usual gait speed) as the screening test. [49] Another difference is the cutoff values of these measurements in Asian populations that differ from those in Caucasians because of ethnicities, body size, lifestyles, and cultural backgrounds. AWGS recommends the cutoff values of the appendicular skeletal muscle mass index of $7.0 \mathrm{~kg} / \mathrm{m} 2$ in men and $5.4 \mathrm{~kg} / \mathrm{m} 2$ in women by using DXA and $7.0 \mathrm{~kg} / \mathrm{m} 2$ in men and $5.7 \mathrm{~kg} / \mathrm{m} 2$ in women, using BIA. Low handgrip strength is suggested to be defined as $<26 \mathrm{~kg}$ for men and $<18 \mathrm{~kg}$ for women, and the cutoff of $0,8 \mathrm{~m} / \mathrm{s}$ for the gait speed [49].

\section{Osteosarcopenia}

As outlined above, osteosarcopenia is the term used to define older adults diagnosed with both low BMD and sarcopenia. Importantly, in this context, DXA may provide useful information as it can be used to access muscle (lean) mass and BMD [9]. 


\section{Clinical Events in Osteosarcopenia}

A systematic review of the Global Burden of Disease Study, published in 2010, noted that the second main contributor to global years lived with disability (YLDs) is the presence of musculoskeletal disorders, affecting nearly 2 billion people worldwide; with falls the 10th greatest specific cause of YLDs worldwide and the 3rd greatest in western and central Europe [50].

Sarcopenia and osteopenia/osteoporosis are two different conditions that act together in the genesis of disability [22]. The bone fragility associated with osteopenia/osteoporosis is a major risk factor for hip fractures, following even minimal trauma. Fractures are common and place an enormous burden on the individuals who suffer them. Approximately $20 \%$ of patients with hip fracture may require long-term nursing home care and only $40 \%$ fully regain their pre-fracture level of independence [40]. A hip fracture equates to 13.7 potential years of life lost in a 65 to 69-year-old woman [51], and in an individual of 80 years old, on average results in a $25 \%$ reduction in life expectancy [52].

Sarcopenia is characterized mainly by the decrease in the number of type II (fast) muscle fibers with significant detrimental effects on muscle strength and balance. Therefore, sarcopenic individuals are at higher risk of falls, which is a well-established contributor to fractures particularly if osteopenia is also present [53]. In addition, there is strong evidence showing that sarcopenia is a predictor of fracture risk in the older population and provides incremental predictive value if integrated with the diagnosis of osteopenia and the use of the FRAX ${ }^{\circledR}$ tool [44]. The incidence of urinary tract infections, aspiration and aspiration pneumonia is also significantly higher in sarcopenic patients $[45,54,55]$. Sarcopenia is also independently associated with frailty, functional impairment, physical disability, institutionalization, decreased quality of life and increased mortality [56-58].

Individuals with osteosarcopenia are at greatest risk, with the additive negative health outcomes predisposed by the two diseases (Figure 3). A study in 680 older fallers in Sydney 
reported that osteosarcopenic subjects were at higher risk of falls and fractures [59]. In addition, in a 2014 cohort with 2,000 community-dwelling men aged $\geq 65$ years, fracture risk was increased 3.5-fold in the presence of osteosarcopenia; significantly higher than having only sarcopenia or osteopenia alone [60]. Indeed, the osteosarcopenic population is at higher risk not only for fractures, but also for depression and impaired mobility [6]. Bone and muscle loss also may be tightly linked to the risk of frailty as shown in a 2015 study conducted in China in which osteosarcopenia was found in $26.3 \%$ of men and $38.5 \%$ of women with frailty and only in $1.6 \%$ and $1.9 \%$ of non-frail men and women respectively [23].

\section{Fig. 3 here}

In terms of impact on health systems, the association between osteosarcopenia and substantially increased morbidity and mortality places an increased financial burden on healthcare services. An American study estimated a lifetime attributable cost of hip fracture in an 80 years old community dweller person to be $\$ 81,300$, and the total yearly cost of all hip fractures in the United States of more than \$20 billion [52]. Also in the United Sates, another study calculated the direct cost of sarcopenia to be $\$ 18.5$ billion in 2000 , represented by hospitalization, nursing home admissions, and home healthcare expenditure [61]. In Switzerland, osteoporotic fractures in women account for more hospital bed days than chronic obstructive pulmonary disease, myocardial infarction and stroke, constituting a major financial burden to the health system [62]. In Europe, an estimate in 2010 calculated the direct cost of all osteoporotic fractures at $€ 29$ billion in the five largest EU countries (France, Germany, Italy, Spain and $\mathrm{UK})$ and $€ 38.7$ billion in $27 \mathrm{EU}$ countries $[63,64]$. 


\section{Treatment}

Osteosarcopenia is a potentially preventable and treatable disease. Most therapeutic interventions target low BMD and sarcopenia separately, but as outlined above, the close association between the two conditions suggests that an integrated interventional approach is likely to be more successful [65].

For the prevention of osteosarcopenia, identification and treatment of modifiable risk factors such as endocrine disorders are fundamental. Additionally, the risk of developing sarcopenia and osteopenia may be attenuated through healthy lifestyle changes that optimize peak bone mass and maintain musculoskeletal health throughout life, including regular physical activity and adequate nutrition (dietary calcium, vitamin D, and protein intake) [65-67].

The early detection of the disease through screening those at higher risk, as shown previously, or by assessing patients with clinical features of osteosarcopenia, who present following a fragility fracture may be helpful to prevent negative outcomes. Simple interventions such as resistance training, adequate protein and calcium dietary intake along associated with maintenance of appropriate levels of vitamin D have been shown to have a dual effect on bone and muscle, resulting in a significant reduction in falls, fractures and therefore disability.

Exercise, particularly progressive resistance exercise has been shown to be a stimulus for muscle protein synthesis, with most exercise trials demonstrating improvements in muscle strength and physical performance measures [21]. The benefits of regular weight-bearing impact and muscle-strengthening exercise which focus on improving agility, strength, posture and balance have been demonstrated [30, 40, 68, 69]. Undertaking exercise at least three times a week for a minimum of 20 minutes has been shown to significantly improve muscle and bone mass, increase muscle strength, reduce or delay functional limitations and prevent falls and fractures in older people $[40,70,71]$. However, although it is considered a highly effec- 
tive and safe therapy for osteosarcopenia, patients with multiple comorbidities (such as neurocognitive and cardiac disorders) may experience obstacles to performing the recommended levels of physical activity [45].

Adequate protein intake is another intervention that has been shown to have potential therapeutic benefit on both sarcopenic and osteopenic patients. Dietary protein has a direct effect on key regulatory proteins and growth factors involved in muscle and bone health by increasing calcium absorption, suppressing parathyroid hormone, and increasing production of IGF-I (a bone and muscle anabolism stimulator) [66]. Protein intake beyond $0.8 \mathrm{mg} / \mathrm{kg}$ body weight/day, mainly of animal proteins, rich in essential amino acids, enhances muscle protein anabolism along with protecting against age-related muscle loss and femoral bone loss [30, 74]. In patients aged 70-79 years, consuming protein at $1.1 \mathrm{~g} / \mathrm{kg}$ body weight/day resulted in less muscle loss at 3-year follow up [73]. Additionally, protein intake, in tandem with exercise has been shown to enhance muscle protein synthesis compared to exercise alone and positively impacts body composition by promoting loss of fat, gain or maintenance of lean mass and preservation of bone $[66,74]$. Some patients have insufficient protein dietary intake and in such cases a dietary supplement containing amino acids and proteins may be considered, although the evidence is not sufficient to show a consistent effect of protein supplementation on muscle mass and function [21]. Ultimately, protein intake should be accompanied by an adequate energy supply to achieve optimal protein utilization.

The European Society for Clinical and Economic Aspects of Osteoporosis and Osteoarthritis (ESCEO) recommends optimal dietary protein intake of 1.0 to $1.2 \mathrm{~g} / \mathrm{kg}$ body weight/day with at least 20 to $25 \mathrm{~g}$ of high quality protein at each main meal [64]. The European Society for Clinical Nutrition and Metabolism (ESPEN) and the PROT-AGE Study Group recommends the same protein intake for healthy older people and 1.2 to $1.5 \mathrm{~g} / \mathrm{kg}$ body 
weight/day for those mal-nourished or at risk of malnutrition $[75,76]$. The distribution of protein intake over the day may be important to allow an appropriate stimulation of postprandial muscle protein synthesis over a day.

Vitamin D plays a role in the homeostasis of bone and muscle. Its deficiency is associated with increased bone resorption and loss of muscle mass and strength in older people [77]. Moreover, a low level of vitamin D is associated with poorer outcomes for frailty, hip fracture and all-cause mortality [78]. Oral vitamin D supplementation between 700 to 800 IU/day has been shown to improve bone and muscle strength, being associated with functional improvement, reduced risk of falls, hip fractures and mortality, but the optimal intake of vitamin D is still uncertain [78-81]. ESCEO also recommend an adequate vitamin D intake at $800 \mathrm{IU} /$ day to maintain serum 25 -hydroxyvitamin D levels $>50 \mathrm{nmol} / \mathrm{L}$ as well as a dietary calcium intake of $1000 \mathrm{mg} /$ day, alongside regular physical activity/exercise undertaken 3-5 times/week in postmenopausal women for the prevention of age-related deterioration of musculoskeletal health [64].

There are already several medications that are administered with the aim of preventing osteoporosis-related fractures. Current osteoporosis treatments have been divided into two groups: anti-resorptives (bisphosphonates and denosumab) and anabolics (teriparatide and abaloparatide). Other novel approaches to osteoporosis treatment that are still being evaluated are the anti-sclerostin antibody (with anabolic effect) and cathepsin $\mathrm{K}$ inhibitor (with anti-resorptive effect) [82]. The United States National Osteoporosis Foundation recommendations are to initiate pharmacologic treatment in patients with fragility fractures; in those with osteoporosis based on BMD measurement by DXA (T-scores $\leq-2.5$ at the femoral neck, total hip, or lumbar spine), and those with a 10 -year hip fracture probability $\geq 3 \%$ or a 10 -year major osteoporosis-related fracture probability $\geq 20 \%$ based on FRAX® tool [40]. However, there is 
no evidence that these medications also have a positive effect on muscle, treating just the "bone aspect" of osteosarcopenia.

As previously discussed, myostatin appears to be a key factor in the integrated physiology of the musculoskeletal system, performing a negative regulation of muscle and bone. Administration of ACVR2B-Fc, a soluble myostatin decoy receptor, has been shown to be well tolerated and resulted in an increase in lean body mass and bone formation markers in postmenopausal women [26, 83-85]. A phase 2 randomized controlled trial showed that a humanized myostatin anti-body leads to increases in appendicular muscle mass and several performance-based measures compared with placebo [86]. However, there are unanswered questions about the clinical efficacy and safety of myostatin targeted treatment. Sustained administration might result in adverse effects, as myostatin is also expressed in cardiac tissue, myostatin inhibition might result in the possibility of cardiomyopathy [85]. Research into anti-myostatin antibodies is still in the experimental phase with more clinical trials needed to clarify their impact on reducing the risk of falls and/or physical dependency as well as safety considerations for this type of treatment [87]. Other pharmacological therapies such as testosterone, growth hormone, insulin like factor-1 have been attempted to treat osteoporosis and sarcopenia, but so far, no clear evidence of their benefits has been found [88-90].

\section{Conclusion and Future Directions}

This review has attempted to summarize the available literature on varying aspects of osteosarcopenia. Although most of the literature in this field has looked at sarcopenia and osteoporosis as two separate entities, we were successfully in summarizing most of the growing evidence looking at osteosarcopenia as a combined syndrome. Although we found an emerging body of evidence, there is still need for more high-quality trials from both basic sciences and clinical research. Standardized clinical and imaging criteria to diagnose osteosarcopenia are 
still lacking. Furthermore, longitudinal studies will be pivotal to determine whether sarcopenia precedes osteopenia/osteoporosis or vice versa. In addition, future studies should aim to better characterize the communication between muscle and bone from an autocrine and endocrine perspective. Overall, this new evidence would generate novel potential therapeutic approaches simultaneously targeting muscle and bone with combined anti-fall and anti-fracture efficacy.

Nevertheless, our knowledge to date shows that osteosarcopenia is a new geriatric syndrome, increasingly prevalent in our ageing population and with potential to lead to poorer outcomes for those patients left undiagnosed and untreated. Substantially associated with increased morbidity and mortality risk, osteosarcopenia contributes to billions in annual health care costs. Bone and muscle loss are strongly interconnected, firstly due to shared risk factors including chronic inflammation related to fatty infiltration of bone marrow and muscle, and most important, owing to the direct mechanic and metabolic interaction between the two tissues. Consequently, it is essential that fracture prevention approaches and post-fracture management include assessment and treatment of the two components of the disease, aiming to reduce the risk of falls and fractures in this high-risk population. As such, more routine use of DEXA scans to evaluate and monitor body composition, along with increased use of simple assessment measures such as hand grip strength and gait speed for older individuals presenting to general practice and geriatric clinics may have a beneficial effect on improving outcomes in elderly patients at risk of or presenting with this disease. Although current pharmacological treatments for osteoporosis have no effect on muscle mass, there is solid evidence that adequate protein and calcium intake, physical resistance exercise and maintaining vitamin D on appropriated levels, can have a dual effect on bone and muscle, all contributing to improving functionality and reducing falls and fracture risk in our older population. 


\section{References}

1. Abimanyi-Ochom J, Watts JJ, Borgström F, Nicholson GC, Shore-Lorenti C, Stuart AL, Zhang Y, Iuliano S, Seeman E, Prince R, March L, Cross M, Winzenberg T, Laslett LL, Duque G, Ebeling PR, Sanders KM (2015) Changes in quality of life associated with fragility fractures: Australian arm of the International Cost and Utility Related to Osteoporotic Fractures Study (AusICUROS). Osteoporos Int 26(6):1781-90.

2. Peterson SJ, Braunschweig CA (2016) Prevalence of sarcopenia and Associated Outcomes in the Clinical Setting. Nut Clin Pract 31(1):40-8

3. Cruz-Jentoft AJ, Baeyens JP, Bauer JM, et al (2010) Sarcopenia: European consensus on definition and diagnosis Report of the European Working Group on Sarcopenia in Older People. Age Ageing 39:412-423

4. Kanis JA, Adachi JD, Cooper C, Clark P, Cummings SR, Diaz-Curiel M, Harvey N, Hiligsmann M, Papaioannou A, D Pierroz D, Silverman SL, Szulc P, and the Epidemiology and Quality of Life Working Group of IOF (2013) Standardising the descriptive epidemiology of osteoporosis: recommendations from the Epidemiology and Quality of Life Working Group of IOF. Osteoporos Int 24(11):2763-2764

5. Curtis E, Litwic A, Cooper C, Dennison E (2015) Determinants of muscle and bone aging. J Cell Physiol 230:2618-2625

6. Huo YR, Suriyaarachchi P, Gomez F, Curcio CL, Boersma D, Muir SW, Montero-Odasso M, Gunawardene P, Demontiero O, Duque G (2015) Phenotype of osteosarcopenia in older individuals with a history of falling. J Am Med Dir Assoc 16(4):290-295

7. Crepaldi G, Maggi S (2005) Sarcopenia and osteoporosis: A hazardous duet. J Endocrinol Invest 28:66-68

8. Levinger I, Phu S, Duque G (2016) Sarcopenia and osteoporotic fractures. Clinical Reviews in Bone and Mineral Metabolism 14(1):38-44 
9. Binkley N, Buehring B (2009) Beyond FRAX: it's time to consider "sarco-osteopenia'”. J Clin Densitom 12:413-416

10. Frost HM (1997) On our age-related bone loss: insights from a new paradigm. J Bone Miner Res 12:1539-1546

11. Cheung AM, Papaioannou A, Morin S (2016) Osteoporosis Canada Scientific Advisory Council. Postmenopausal Osteoporosis. N Engl J Med 374:2095-2097

12. Wright NC, Looker A, Saag K, Curtis JR, Dalzell ES, Randall S, Dawson-Hughes B (2014) The re-cent prevalence of osteoporosis and low bone mass based on bone mineral density at the femoral neck or lumbar spine in the United States. J Bone Miner Res 29(11):2520-2526

13. Office of the Surgeon General (US) (2004) Bone health and osteoporosis: a report of the Surgeon General. Office of the Surgeon General (US), Rockville (MD). Available from: http://www.ncbi.nlm.nih.gov/books/NBK45513/. Accessed 26 August 2016

14. Amin S, Achenbach SJ, Atkinson EJ, Khosla S, Melton LJ III (2014) Trends in fracture incidence: a population-based study over 20 years. J Bone Miner Res 29:581-589

15. Cooper C, Campion G, Melton LJ (1992) Hip fractures in the elderly: a world-wide projection. Osteoporos Int 2:285-289

16. Gullberg B, Johnell O, Kanis JA (1997) World-wide projections for hip fracture. Osteoporos Int 7:407-413

17. Hughes VA, Frontera WR, Roubenoff R, Evans WJ, Singh MA (2002) Longitudinal changes in body composition in older men and women: role of body weight change and physical activity. Am J Clin Nutr 76:473-481

18. Lauretani F, Russo CR, Bandinelli S, Bartali B, Cavazzini C, Di Iorio A, Corsi AM, Rantanen T, Guralnik JM, Ferrucci L (2003) Age- associated changes in skeletal muscles and their effect on mobility: an operational diagnosis of sarcopenia. J Appl Physiol 95:1851-1860 
19. Lexell J, Taylor CC, Sjostrom M (1988) What is the cause of the ageing atrophy? Total number, size and proportion of different fiber types studied in whole vastus lateralis muscle from 15- to 83-year-old men. J Neurol Sci 84(2-3):275-294

20. von Haehling S, Morley JE, Anker SD (2012) From muscle wasting to sarcopenia and myopenia: up-date. J Cachexia Sarcopenia Muscle 3:213-217

21. Cruz-Jentoft AJ, Landi F, Schneider SM, Zúñiga C, Arai H, Boirie Y, Chen LK, Fielding RA, Martin FC, Michel JP, Sieber C, Stout JR, Studenski SA, Vellas B, Woo J, Zamboni M, Cederholm T (2014) Prevalence of and interventions for sarcopenia in ageing adults: a systematic review. Report of the International Sarcopenia Initiative (EWGSOP and IWGS). Age Ageing 43(6):748-59

22. Di Monaco M, Vallero F, Di Monaco R, Tappero R (2011) Prevalence of sarcopenia and its association with osteoporosis in 313 older women following a hip fracture. Arch Gerontol Geriatr 52:71-74

23. Wang YJ, Wang Y, Zhan JK, Tang ZY, He JY, Tan P, Deng HQ, Huang W, Liu YS (2015) Sarco-Osteoporosis: Prevalence and Association with Frailty in Chinese Community-Dwelling Older Adults. Int J Endocrinol 2015:482940

24. Boirie Y (2009) Physiopathological mechanism of sarcopenia. J Nutr Health Aging. $13(8): 717-23$

25. Karasik D, Kiel DP (2008) Genetics of the musculoskeletal system: a pleiotropic approach. J. Bone Miner. Res 23:788-802

26. Kawao N, Kaji H (2015) Interactions between muscle tissues and bone metabolism. J Cell Biochem 116:687-695

27. Isaacson J, Brotto M (2014) Physiology of mechanotransduction: How do muscle and bone “talk” to one another? Clin Rev Bone Miner Metab 12:77-85 
28. Maugeri D, Russo MS, Franze C, Motta V, Motta M, Destro G, Speciale S, Santangelo A, Panebian-co P, Malaguarnera M (1998) Correlations between C-reactive protein, interleukin6, tumor necrosis factor-alpha and body mass index during senile osteoporosis. Arch Gerontol Geriatr 27:159-163

29. Ng A, Duque G (2010) Osteoporosis as a lipotoxic disease. BoneKEy-Osteovision 7:108-123

30. Demontiero O, Boersma D, Suriyaarachchi P, Duque G (2014) Clinical Outcomes of Impaired Muscle and Bone Interactions. Clinic Rev Bone Miner Metab 12:86-92

31. Burr DB (1997) Muscle strength, bone mass, and age-related bone loss. J Bone Miner Res $12: 1547-1551$

32. Sjoblom S, Suuronen J, Rikkonen T, Honkanen R, Kroger H, Sirola J (2013) Relationship between postmenopausal osteoporosis and the components of clinical sarcopenia. Maturitas 75(2):175-180

33. Isaacson J, Brotto M (2014) Physiology of mechanotransduction: How do muscle and bone "talk” to one another? Clin Rev Bone Miner Metab 12:77-85

34. Mera P, Laue K, Ferron M, Confavreux C, Wei J, Galán-Díez M, Lacampagne A, Mitchell SJ, Matti-son JA, Chen Y, Bacchetta J, Szulc P, Kitsis RN, de Cabo R, Friedman RA, Torsitano C, McGraw TE, Puchowicz M, Kurland I, Karsenty G (2017) Osteocalcin Signaling in Myofibers Is Necessary and Sufficient for Optimum Adaptation to Exercise. Cell Metab $10 ; 25(1): 218$

35. Sassoli C, Pini A, Chellini F, et al (2012) Bone marrow mesenchymal stromal cells stimulate skeletal myoblast proliferation through the paracrine release of VEGF. PLoS One 7(7):e37512

36. Tagliaferri C, Wittrant Y, Davicco MJ, et al (2015) Muscle and bone, two interconnected tissues. Ageing Res Rev 21:55-57

37. Kaji H (2014) Interaction between muscle and bone. J Bone Metab 21:29-40 
38. WHO Study Group (1994) Assessment of fracture risk and its application to screening for postmenopausal osteoporosis. World Health Organ Tech Rep Ser 843:1-129

39. Baim S, Binkley N, Bilezikian JP, et al (2008) Official Positions of the International Society for Clinical Densitometry and executive summary of the 2007 ISCD Position Development Conference. J Clin Densitom 11(1):75-91

40. Cosman F, de Beur SJ, LeBoff MS, et al (2014) Clinician's Guide to Prevention and Treatment of Osteoporosis. Osteoporos Int 2014 25:2359-2381

41. Nordin C (2011) Screening for osteoporosis: U.S. preventive services task force recommendation statement. Ann Intern Med 155(4):276

42. Papaioannou A, Morin S, Cheung AM, et al (2010) Clinical practice guidelines for the diagnosis and management of osteoporosis in Canada: Summary. CMAJ 182:1864-1873

43. Baumgartner RN, Koehler KM, Gallagher D, Romero L, Heymsfield SB, Ross RR et al (2015) Epidemiology of sarcopenia among the elderly in New Mexico. Am J Epidemiol. $147: 755-763$

44. Oliveira A, Vaz C (2015) The role of sarcopenia in the risk of osteoporotic hip fracture. Clin Rheumatol 34(10):1673-1680

45. Hida T, Harada A, Imagama S, Ishiguro N (2003) Managing sarcopenia and its related-fractures to improve quality of life in geriatric populations. Aging Dis 26;5(4):226-237

46. Gonzalez MC, Heymsfield SB (2017) Bioelectrical impedance analysis for diagnosing sarcopenia and cachexia: what are we really estimating? J Cachexia Sarcopenia Muscle. 8(2):187189

47. Rolland Y, Lauwers-Cances V, Cournot M et al (2003) Sarcopenia, calf circumference, and physical function of elderly women: a cross-sectional study. J Am Geriatr Soc 51:1120-1124

48. Fried LP, Tangen CM, Walston J et al (2001) Frailty in older adults: evidence for a phenotype. J Gerontol A Biol Sci Med Sci 56:146-56 
49. Chen LK, Liu LK, Woo J, Assantachai P, Auyeung TW, Bahyah KS, Chou MY, Chen LY, Hsu PS, Krairit O, Lee JS, Lee WJ, Lee Y, Liang CK, Limpawattana P, Lin CS, Peng LN, Satake S, Suzuki T, Won CW, Wu CH, Wu SN, Zhang T, Zeng P, Akishita M, Arai H (2014) Sarcopenia in Asia: consensus report of the Asian Working Group for Sarcopenia. J Am Med Dir Assoc 15(2):95-101

50. Vos T, Flaxman AD, Naghavi M, Lozano R, Michaud C, Ezzati M, et al (2010) Years live with disability (YLDs) for 1160 sequelae of 289 diseases and injuries 1990-2010: a systematic analysis for the Global Burden of Disease Study 2010. Lancet 380:2163-2196

51. Center JR, Nguyen TV, Schneider D (1999) Mortality after all major types of osteoporotic fracture in men and women: An observational study. Lancet 353:878-882

52. Braithwaite RS, Col NF, Wong J (2003) Estimating hip fracture morbidity, mortality and costs. J Am Geriatr Soc 51:354-370

53. Baumgartner RN, Koehler KM, Gallagher D et al (1998) Epidemiology of sarcopenia among the elderly in New Mexico. Am J Epidemiol 147:755-763

54. Pfisterer MH, Griffiths DJ, Schaefer W, Resnick NM (2006) The effect of age on lower urinary tract function: a study in women. J Am Geriatr Soc 54:405-412

55. Chen HI, Kuo CS (1989) Relationship between respiratory muscle function and age, sex, and other factors. J Appl Physiol 66:943-948

56. Janssen I, Heymsfield SB, Ross R (2002) Low relative skeletal muscle mass (sarcopenia) in older per-sons is associated with functional impairment and physical disability. J Am Geriatr Soc 50(5):889-896

57. Hairi NN, Cumming RG, Naganathan V, Handelsman DJ, Le Couteur DG, Creasey H, et al (2010) Loss of muscle strength, mass (sarcopenia), and quality (specific force) and its relationship with functional limitations and physical disability: the Concord health and ageing in men project. J Am Geriatr Soc 58:2055-2062 
58. Drey M, Sieber CC, Bertsch T, Bauer JM, Schmidmaier R (2015) Osteosarcopenia is more than sarcopenia and osteopenia alone. Aging Clin Exp Res Published on-line DOI: 10.1007/s40520-015-0494-1. Accessed 26 August 2016

59. Huo YR, Suriyaarachchi P, Gomez F, Curcio CL, Boersma D, Gunawardene P, Demontiero O, Duque G (2015) Comprehensive nutritional status in sarco-osteoporotic older fallers. J Nutr Health Aging. 19(4):474-80.

60. Yu R, Leung J, Woo J (2014) Incremental predictive value of sarcopenia for incident fracture in an elderly Chinese cohort: results from the Osteoporotic Fractures in Men (MrOs) Study. J Am Med Dir Assoc 15:551-558

61. Janssen I, Shepard DS, Katzmarzyk PT, Roubenoff R (2004) The healthcare costs of sarcopenia in the United States. J Am Geriatr Soc 52(1):80-85

62. Lippuner K, von Overbeck J, Perrelet R, Bosshard H, Jaeger P (1997) Incidence and direct medical costs of hospitalizations due to osteoporotic fractures in Switzerland. Osteoporos Int. 7(5):414-425.

63. Strom O, Borgstrom F, Kanis JA, Compston JE, Cooper C, McCloskey E, Jonsson B (2011) Osteoporosis: burden, health care provision and opportunities in the EU. A report prepared in collaboration with the International Osteoporosis Foundation (IOF) and the European Federation of Pharmaceutical Indus-try Associations (EFPIA) 6:59-155

64. Kanis JA, McCloskey EV, et al. and on behalf of the Scientific Advisory Board of the European Society for Clinical and Economic Aspects of Osteoporosis and Osteoarthritis (ESCEO) and the Committee of Scientific Advisors of the International Osteoporosis Foundation (IOF) (2013) European guidance for the diagnosis and management of osteoporosis in postmenopausal women. Osteoporosis International 24(1):23-57

65. Reginster JY, Beaudart C, Buckinx F, Bruyère O (2016) Osteoporosis and sarcopenia: two diseases or one? Curr Opin Clin Nutr Metab Care 19(1):31-36 
66. Rizzoli R, Stevenson JC, Bauer JM, et al (2014) The role of dietary protein and vitamin D in maintaining musculoskeletal health in postmenopausal women: a consensus statement from the European Society for Clinical and Economic Aspects of Osteoporosis and Osteoarthritis (ESCEO). Maturitas 79:122-132

67. Daly RM, Duckham RL, Gianoudis J (2014) Evidence for an interaction between exercise and nutrition for improving bone and muscle health. Curr Osteoporos Rep 12:219-226

68. Gianoudis J, Bailey CA, Sanders KM, Nowson CA, Hill K, Ebeling PR, Daly RM (2012) Osteocise: strong bones for life: protocol for a community-based randomised controlled trial of a multi- modal exercise and osteoporosis education program for older adults at risk of falls and fractures. BMC Musculoskelet Disord 13:78

69. Hunter GR, McCarthy JP, Bamman MM (2004) Effects of resistance training on older adults. Sports Med 34:329-348

70. Choi M, Hector M (2012) Effectiveness of intervention programs in preventing falls: a systematic re-view of recent 10 years and meta-analysis. J Am Med Dir Assoc 13(2):188.13188.e21

71. Sherrington C, Whitney JC, Lord SR, Herbert RD, Cumming RG, Close JC (2008) Effective exercise for the prevention of falls: a systematic review and meta-analysis. J Am Geriatr Soc 56(12):2234-2243

72. Genaro PS, Martini LA (2010) Effect of protein intake on bone and muscle mass in the elderly. Nutr Rev 68:616-623

73. Houston DK, Nicklas BJ, Ding J, et al (2008) Dietary protein intake is associated with lean mass change in older, community-dwelling adults: the Health, Aging, and Body Composition (Health ABC) Study. Am J Clin Nutr 87:150-155 
74. Holm L, Olesen JL, Matsumoto K, et al (2008) Protein-containing nutrient supplementation following strength training enhances the effect on muscle mass, strength, and bone formation in postmenopausal women. J Appl Physiol 105:274-281

75. Deutz NE, Bauer JM, Barazzoni R, Biolo G, Boirie Y, Bosy-Westphal A, Cederholm T, CruzJentoft A, Krznariç Z, Nair KS, Singer P, Teta D, Tipton K, Calder PC (2014) Protein intake and exercise for optimal muscle function with aging: recommendations from the ESPEN Expert Group. Clin Nutr 33(6):929-36

76. Bauer J, Biolo G, Cederholm T, Cesari M, Cruz-Jentoft AJ, Morley JE, Phillips S, Sieber C, Stehle P, Teta D, Visvanathan R, Volpi E, Boirie Y (2013) Evidence-based recommendations for optimal dietary protein intake in older people: a position paper from the PROT-AGE Study Group. J Am Med Dir Assoc 14(8):542-59

77. Bischoff-Ferrari HA, Dietrich T, Orav EJ, et al (2004) Higher 25-hydroxyvitamin D concentrations are associated with better lower-extremity function in both active and inactive persons aged $>$ or $=60 \mathrm{y}$. Am J Clin Nutr 80:752-758

78. Rizzoli R, Boonen S, Brandi ML, et al (2013) VitaminD supplementation in elderly or postmenopausal women: a 2013 update of the 2008 recommendations from the European Society for Clinical and Economic Aspects of Osteoporosis and Osteoarthritis (ESCEO). Curr Med Res Opin 29:305-313

79. Bischoff-Ferrari HA, Willett WC, Wong JB, Giovannucci E, Dietrich T, Dawson-Hughes B (2005) Fracture prevention with vitamin D supplementation: a meta-analysis of randomized controlled trials. JAMA 293:2257-2264

80. Bischoff-Ferrari HA, Dawson-Hughes B, Willett WC, Staehelin HB, Bazemore MG, Zee RY, et al (2004) Effect of Vitamin D on falls: a meta-analysis. JAMA 291:1999-2006 
81. Barr R, Macdonald H, Stewart A, McGuigan F, Rogers A, Eastell R, et al (2010) Association between vitamin D receptor gene polymorphisms, falls, balance and muscle power: results from two independent studies (APOSS and OPUS). Osteoporos Int 21: 457-466

82. Duque G (2013) Osteoporosis in older persons: current pharmacotherapy and future directions. Expert Opin Pharmacother 14(14):1949-1958

83. Bradley L1, Yaworsky PJ, Walsh FS (2008) Myostatin as a therapeutic target for musculoskeletal dis-ease. Cell Mol Life Sci 65(14):2119-2124

84. Buehring B1, Binkley N (2013) Myostatin--the holy grail for muscle, bone, and fat? Curr Osteoporos Rep 11(4):407-414

85. Attie KM, Borgstein NG, Yang Y, Condon CH, Wilson DM, Pearsall AE, et al (2013) A single ascending-dose study of muscle regulator ACE-031 in healthy volunteers. Muscle Nerve $47(3): 416-423$

86. Becker C, Lord SR, Studenski SA, Warden SJ, Fielding RA, Recknor CP, et al (2015) Myostatin antibody (LY2495655) in older weak fallers: a proof-of-concept, randomised, phase 2 trial. Lancet Diabetes Endocrinol 3(12):948-57

87. Parise G, Snijders T (2015) Myostatin inhibition for treatment of sarcopenia. Lancet Diabetes Endocrinol 3(12):917-8

88. Basaria S, Coviello AD, Travison TG, Storer TW, Farwell WR, Jette AM, et al (2010) Adverse events associated with testosterone administration. N Engl J Med 363:109-122

89. Papadakis MA, Grady D, Black D, Tierney MJ, Gooding G, Schambelan M, et al (1996) Growth hormone replacement in healthy older men improves body composition but not functional ability. Ann Intern Med 124:708

90. Thompson J, Butterfield G, Gylfadottir U, Yesavage J, Marcus R, Hintz R, et al (1998) Effects of human growth hormone, insulin-like growth factor I, and diet and exercise on body composition of obese postmenopausal women. J Clin Endocrinol Metab 83:1477-1484 


\section{Tables}

Table 1. Methods to measure mass, strength and physical performance. Adapted from EWGSOP [3]

\begin{tabular}{ll}
\hline Muscle mass & $\begin{array}{l}\text { Computed Tomography } \\
\text { Magnetic Resonance Imaging } \\
\text { Dual X-ray absorptiometry (DXA) } \\
\text { Bioelectrical impedance analysis (BIA) } \\
\text { Anthropometry (calf circumference) }\end{array}$ \\
Muscle strength & $\begin{array}{l}\text { Handgrip strength } \\
\text { Knee flexion an extension } \\
\text { Peak expiratory flow }\end{array}$ \\
Physical \\
performance & $\begin{array}{l}\text { Timed up and go test } \\
\text { Gait speed } \\
\text { Short physical performance battery } \\
\text { Stair climb power test }\end{array}$ \\
\hline
\end{tabular}

Table 2. Cut-off points of handgrip strength. Adapted from EWGSOP [3]

\begin{tabular}{llcc}
\hline Men & \multicolumn{3}{c}{ Women } \\
$\begin{array}{l}\text { BMI } \\
\mathbf{( k g} / \mathbf{m} 2)\end{array}$ & $\begin{array}{l}\text { Handgrip strength } \\
(\mathbf{k g})\end{array}$ & $\begin{array}{l}\text { BMI } \\
\mathbf{( k g} / \mathbf{m} 2)\end{array}$ & $\begin{array}{l}\text { Handgrip strength } \\
\mathbf{( k g )}\end{array}$ \\
\hline$\leq 24$ & $\leq 29$ & $\leq 23$ & $\leq 17$ \\
$24.1-26$ & $\leq 30$ & $23.1-26$ & $\leq 17.3$ \\
$26.1-28$ & $\leq 30$ & $26.1-29$ & $\leq 18$ \\
$>28$ & $\leq 32$ & $>29$ & $\leq 21$ \\
\hline
\end{tabular}




\section{Figure Legends}

Figure 1. Ostesarcopenia Pathophysiology. GH/IGF-I, growth hormone-/insulin-like growth factor-I, FGF2, fibroblast growth factor 2; FAM5C, family with sequence similarity 5, member, C; IL, interleukin; MMP-2, matrix metalloproteinase-2; MGF, mechanogrowth factor; VEGF, vascular endothelial growth factor; HGF, hepatocyte growth factor. Adapted from Kawao et al. [26]

Figure 2. EWGSOP modified algorithm for screening and classification of sarcopenia. Adapted from Cruz-Jentoff et al. [3]

Figure 3. Higher prevalence of falls and fractures in osteosarcopenic subjects. The figure compares the mean $( \pm \mathrm{SD})$ number of self-reported falls (past 6 months) $(\mathrm{A})$ and fractures (last 5 years) (B) amongst the participants of the Nepean Osteoporosis and Frailty Study. The osteosarcopenic (OSP) group showed the higher self-reported prevalence of falls and fractures as compared with the other groups: SR: Sarcopenic, OP: Osteopenic/osteoporotic. As expected, falls were more prevalent in the SP group as compared with the OP and normal groups. Fractures were more prevalent in the OP group as compared with the normal and SP groups. ${ }^{*} \mathrm{p}<0.01 ; \# \mathrm{p}<0.01$ vs. normal (fallers with no SP/no OP). Adapted from Huo et al. [59] 


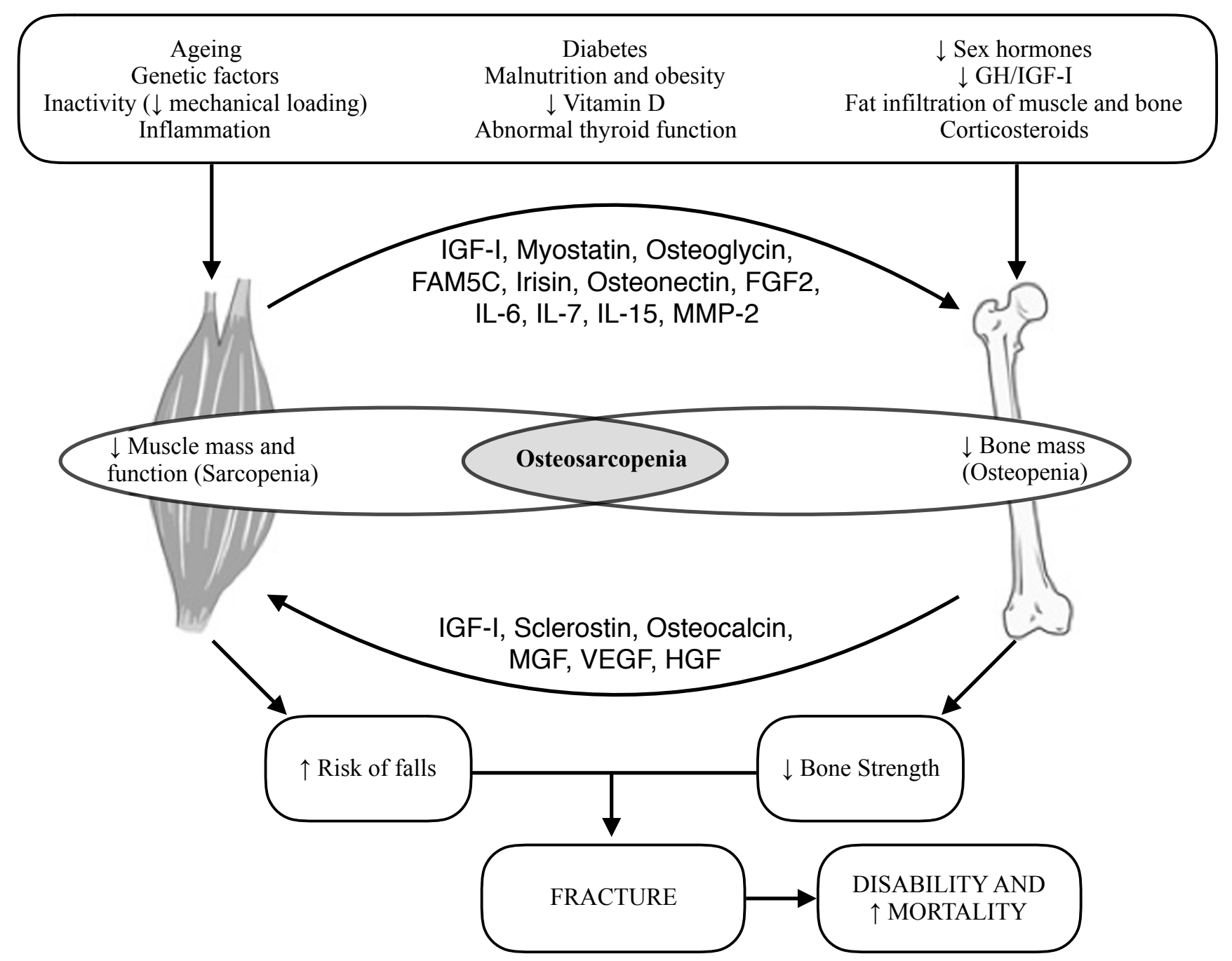




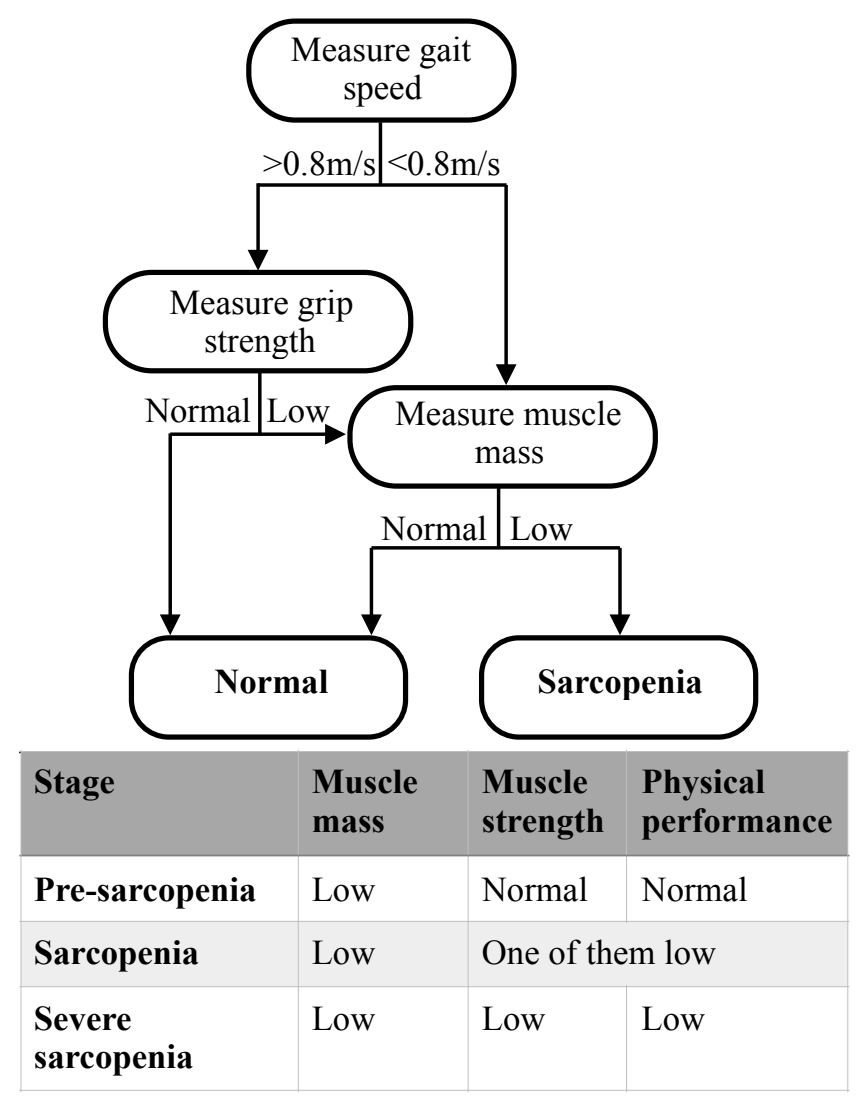




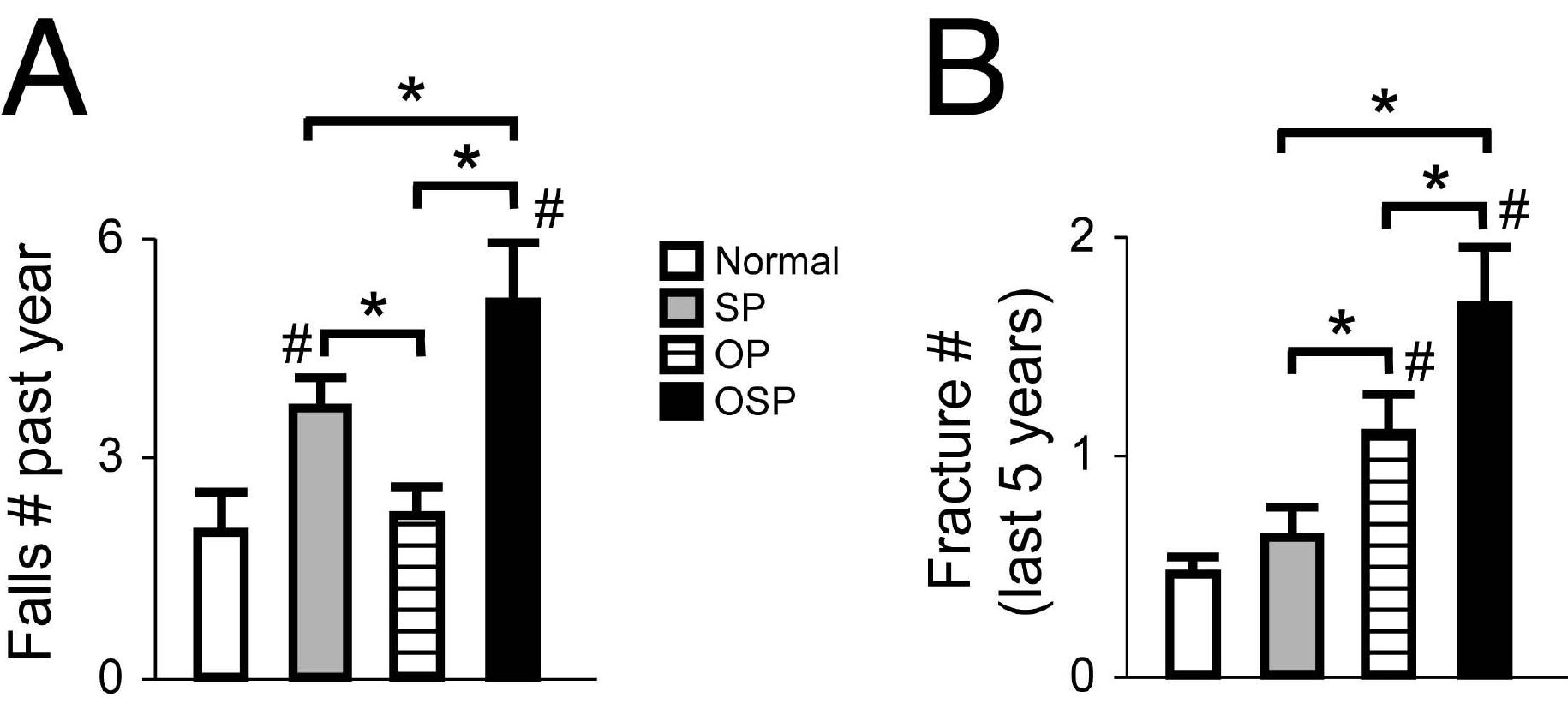

